\title{
Information Resources Co-construction and Sharing of Higher Education
}

\author{
Tian Juan ${ }^{1}$ \\ ${ }^{1}$ Changsha Aeronautical Vocational and Technical College, Changsha, Hunan, China \\ Correspondence: Tian Juan, Changsha Aeronautical Vocational and Technical College, No. 348, Tiyuan Road, \\ Yuhua District, Post Code: 410014, Changsha City, Hunan Province, China. Tel: 86-0138-7594-3352. E-mail: \\ lovejuan13@yeah.net
}

\author{
Received: January 1, $2017 \quad$ Accepted: January 13, $2017 \quad$ Online Published: March 24, 2017 \\ doi:10.5539/ass.v13n4p65 URL: https://doi.org/10.5539/ass.v13n4p65
}

The research reported here is supported by the project with Hunan province education science "13th Five Year Plan" of 2016 English teaching research subject, Project name: The Construction and Application Research on college English Flipped-class deep learning field on SPOC, Project Grant No.:XJK16BYY02; phased result of research project of Changsha Aeronautical Vocational and Technical College, Project name: The construction and Application of School-based Higher Vocational English Micro-class Resources, Project Grant No.: YC1508.

\begin{abstract}
With the rapid development of information technology and education, there occurred several problems in higher education information resource construction and sharing, such as incomplete infrastructure, low overall resources level, insufficient information resources application, low teachers' information literacy and imperfect resource sharing mechanism. Under the current environment, it's necessary to establish a set of information resources co-construction and sharing education service system to balance resources sharing and improve the sharing mechanism. Also to improve colleges' management, to promote college teachers' development, to adapt to ubiquitous learning and to realize resource sharing.
\end{abstract}

Keywords: information teaching resources, co-construction and sharing, higher education

\section{The Implication of Information Resources in Higher education}

The information resources of higher education can be understood as the composition of the curriculum resources learning resources information tools and the service platform as the technology carrier, with the application of computer technology, communication technology and network technology. Resource construction is based on user requirements, system planning, design, development, selection, resources collection and the formation of resources system. To reflect the meaning of "common", co-construction should emphasis participating as well as construction. Co-construction aims at sharing, which is to provide resource service.

\section{The Development of Higher Education Information Teaching Resources}

The concept of education informatization was introduced in the 1990s, characterized by using computer assisted instruction (CAI) resources construction. At that time, resources are still the dispersion of demonstration on resources, the auxiliary properties of the traditional teaching mode of paper textbooks or simple electronic teaching materials. The concept of resource Library began to form in the late $90 \mathrm{~s}$, which means the structural systematic direction of resources construction. To solve technical problems of database such as heterogeneous and homogeneous interface, the corresponding standards of repository construction carried out. At present, China has made great progress in infrastructure construction of digital education and the resources development and application. With the development of big data and cloud technology, the construction of the resource is generating from unidirection to multidirectional interaction, also more attention has been given to the content resources platform and network service system construction. Higher education information resources construction is moving toward to co-construction and sharing and the direction of mutual fusion.

Chinese higher education information resource construction has been developing greatly both in the number of the repository and resources and in the way of promotion or various resources applications. Which has played an important role for the teaching reform of higher education informatization teachers' innovation in informatization 
teaching and the promotion of students' autonomous learning.

\section{The Existing Problem of Higher Education Information Resources Construction}

Higher education informatization construction in our country has got a rapid development, but the current rapid development also brought new requirements for informational teaching innovation. On the issue of information resource construction, there exists the following deficiencies.

\subsection{Inadequate Infrastructure}

Now, there has been a basic coverage of the broadband and campus network in colleges and universities, and the network structure is relatively reasonable to meet the use of external information resources. But in the aspect of hardware infrastructure, many higher institutions' multimedia classroom and campus network construction do not meet the standard. More colleges and universities are lack of infrastructure software platform for system network teaching, and there are many shortcomings in terms of resources construction and sharing.

\subsection{Low Resource Level}

Education information resources should include core video, courseware, case studies, exercises, expanding task, such as testing and teaching tool as a system. The current resource overall level is still low, especially in the absence of a shared digital resources system of high quality. Currently teaching database is mostly the accumulation of the teaching material content, there are some problems such as low resource levels and single repetition. Part of the excellent resources scattered in the hands of individual teachers without guidance of sharing mechanism. For the Repository, the construction are mainly completed by teachers, the professional characteristics is not obvious though the discipline system is clear. Repository are mainly concentrated in the content of the teaching service but not professional education. The construction of the repository are lack of overall design and interactive feedback, which didn't pay attention to the sustainable development.

\subsection{Insufficient Information Resources Application}

Higher education informatization is in the groping stage of fusing teaching resources and the model of practical teaching. Many colleges are in a state of idle after the completion of the repository. The strength and depth of resources application are not sufficient. It mostly focuses on the shallow usage of multimedia courseware or supplement class teaching. There are still many difficulties in resources interactive usage utilization rate promotion and sharing.

\subsection{Low Teachers' Information Literacy}

College teacher's information literacy is another determinant of the resource sharing, as the main builders and users of resources co-construction and sharing, the quality of teachers' information literacy determines the quality of information resources construction the validity of the information resources practice and the informatization teaching efficiency.

\subsection{Imperfect Resource Sharing Mechanism}

There are many obstacles in the current implementation of resources sharing. The organization and management of the government the running mode and process of resource sharing are all lack of unified system guarantee. Different colleges and universities developed different network platform, which leads to disunity of compatible standard. It is difficult to realize resources sharing because of their different interest. It is more difficult to achieve social resources sharing for the lack of enterprise and external coordination construction mechanism. Therefore, there is urgent need from the policy level to ensure the resources construction and application of operation mechanism.

\section{The Characteristics of Higher Education Information Resource Co-construction and Sharing}

Resources public service platform is the important carrier of sharing education resource, construction and application. Due to the particularity of education, the process of teaching and learning interaction and network education community communication will form a large number of generative resources. For this purpose, the generation and application of these resources according to some principles will achieve maximum intensive sharing of resources and promote positive interaction between construction and use of resources, therefore form the resource service cloud model available to classroom teaching the teachers and students.

\subsection{Openness}

The co-construction and sharing of information resources is the openness of co-construction and sharing. It breaks down barriers between school and region. Firstly, school can construct and share resources of high quality within the school scope. Secondly, the department of education and the education technology enterprises and the 
public can construct and share resources together. Thirdly, this is the co-construction and sharing of all kinds of resources for all sorts of technology platform to a greater range.

\subsection{Sustainability}

The co-construction and sharing of information resources is the sustainability of co-construction and sharing. Various ways should be used to improve the overall level of the informatization education resources to avoid single-minded and unipolarity. For example, to collect resources in distribution to absorb users to participate in the resources construction to generate user' evaluation and recommendation in usage.

\subsection{Innovation}

The co-construction and sharing of information resources is the innovation of co-construction and sharing. The innovation should be the key point to support innovative study through new learning resources. Based on the exploration, the teacher should become a common cooperation learner and thinker through resource sharing. The students should be able to understand, analyze their progress in interdisciplinary fields of study to build support for knowledge construction. Under the guidance of the principles of innovation, both teachers and students should enhance understanding and practice of the generation and application of resources to promote teacher's professional development and students' all-round development.

\section{The Construction of Higher Education Information Resource Co-construction and Sharing}

The overall goal of Higher education information resource construction is the construction of a integrating information education resources co-construction and sharing s service system, based on all kinds of advanced information technology under the network environment, to promote exploitation utilization of public information resources sharing to enhance the level of public service informatization and maximize meet user' demand for higher education information resources and to promote the education informatization level continuously to the modernization of education. Specific content can be reflected in the following aspects:

\subsection{The Construction of the Informatization Teaching Resources}

Teaching resources construction should be set out from the students' demand under the guidance of the teaching goal. The construction should contain micro class core resources, network teaching plans, teaching design, operation practice, the development of performance testing, and other supporting teaching resources. Also, it should include online community interaction regulation, questions solving, communication and development in different platforms between colleges and universities.

\subsection{The Construction of Hardware Environment}

Upgrade the existing communication network construction such as education network and campus network to realize the entire network coverage. Develop learning resources sharing platform from formulating information technology standards first in the application then to meet the final realization of information resources sharing between different platforms. Increase the construction of multimedia classrooms, language lab, electronic reading room, network classroom and other infrastructure construction.

\subsection{The Development of Teachers' Information Literacy}

Information resources are not only the ability training content of teacher's information literacy but also the support of auxiliary training. On the basis of resource sharing service platform, to build a new system of training resources, gathering resources and services, trade and communication, promoting resources processing generated resources, development of curriculum resources, in order to satisfy the demands of teachers' professional personalized learning

\subsection{Balance of Resources Co-construction}

Higher education information resources co-construction and sharing should concern and apply the key technology of cloud computing and big data.

Data mining and study analysis based on large data could speculate more accurate data for individualized learning. Based on cloud computing architecture, centralized management platform and resource sharing, we can really realize the connectivity of education information network and improve utilization efficiency and safety stability of resource.

\subsection{Formulation of Sharing Mechanism}

With the development of information technology and the education reform, as a complicated system engineering, it is necessary to form effective mechanism participating with the government, enterprises and colleges for the co-construction and sharing of education information resources. The government should attach great importance 
to overall planning and provision of public services through policy guidance to promote higher vocational education and balance development of digital resource planning. At the same time, the balance of education resources could improve the level of the development of the informatization construction of hardware and software and develop education information resources construction standard. As the main body of education information resources construction, higher education should give full play to the school-based resources construction to make the resources sharing of information technology become possible between colleges, cities and even the countries

\section{The Significance of Higher Education Information Resource Construction}

Higher education information resources co-construction and sharing should base on the improvement of information awareness and quality of the whole people, train skilled and applied professionals and satisfy the aspirations of the value of lifelong education and lifelong learning. It benefits the college and management departments to carry out the services, to promote personalized "one-stop" services, to accelerate the construction of teaching resources and orderly implementation of communication platform. It is in favor of standardized management of data retrieval, intelligent collection and analysis, and the construction of information system as IC card system and digital library system and so on. It also helps the construction and development of teachers' team, enhance teachers' awareness of innovation and improve teachers' information literacy of teaching. By providing rich resources and standard curriculum, teacher can communicate across the country from students' demands to improve the overall teaching level and realize the informatization teaching innovation through independent course setup and data intelligent monitoring and evaluation. It makes for the adjustment of the ubiquitous learning style under the environment of informatization, hence resources construction can be based on demand to prominent feature and meet different learners' goals of self development and promote the comprehensive development of the learners. Outside agencies can realize resources sharing in whole society, and the participation of external social enterprise can make full use of shared network resources to carry out vocational training and use rich resources of autonomous learning to improve vocational skills and literacy.

\section{References}

Chen, L. (2011). Reach on the construction of deep study of network learning resources. E-Education Research, 12, 69-75.

Hu, L. L. (2012). The study on construction on strategy of Excellent Resource: Sharing Course. Journal of Distance Education, 6, 80-85

Sun, Y. T., Wang, Y. T., \& Ma, G. G. (2012). The co-construction and Sharing of Distance Education Resources in Higher College. China Adult Education, 22, 23-26

\section{Copyrights}

Copyright for this article is retained by the author(s), with first publication rights granted to the journal.

This is an open-access article distributed under the terms and conditions of the Creative Commons Attribution license (http://creativecommons.org/licenses/by/4.0/). 